\title{
TI.105.1
}

\section{Process to Maintain Baseline Expectations by InCommon and its Members}

(superseded by TI.105.2)

- PDF: Processes to Maintain Baseline Expectations.pdf

- Text: Processes to Maintain Baseline Expectations.txt

\section{More Information}

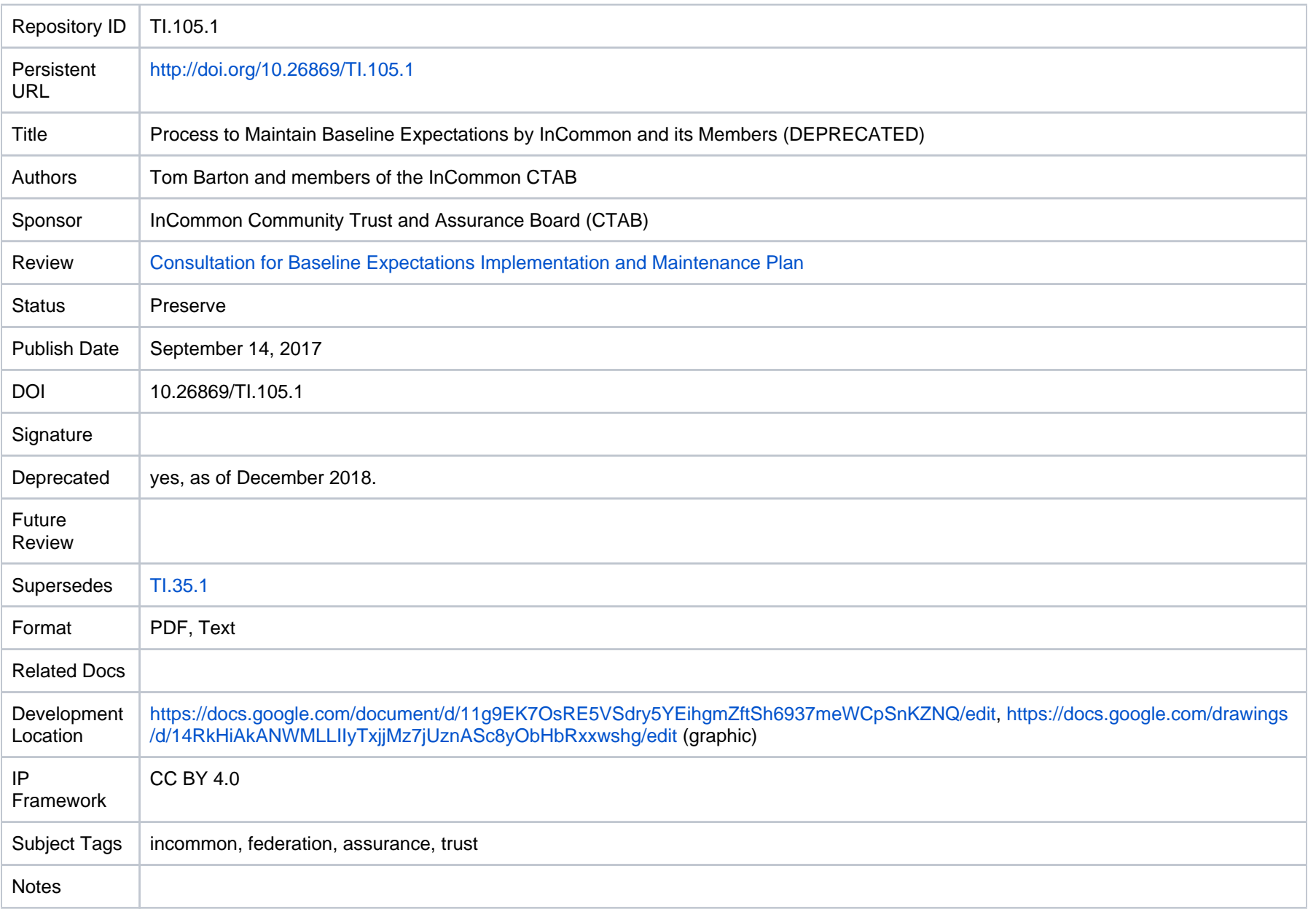

